\title{
Contra a Noção de Parte Formal: uma Resposta A KATHRIN KOSLICKI
}

AgAinst THE VERY NOTION OF A FORMAL PART: A RESPONSE TO KATHRIN KOSLICKI

\author{
RHAMON DE OLIVEIRA NUNES \\ Universidade Federal do Rio de Janeiro, Universidade do Estado do Rio Grande do Norte, BRAZIL \\ rhamon.oliveira@gmail.com
}

\begin{abstract}
In her 2008 book The Structure of Objects, Kathrin Koslicki defends an Aristotelian mereological theory to describe the nature of composite objects. This theory has at its heart the idea that composite objects are fusions of material and formal parts, that is, it is a kind of neo-hylomorphism. The main motivation behind the adoption of this thesis is the rejection of certain compositional theories, especially mereological universalism defended by David Lewis (1986 and 1991). However, I shall argue that none of Koslicki's arguments are sufficient to establish the postulation of formal parts. The reason for this is that the motivation that lead her to a commitment to such entities are not only unjustified, but it is also possible to solve the problems that she raises without appealing to the very notion of formal parts.
\end{abstract}

Keywords: metaphysics • mereology • composition • structure

\section{Introdução}

Em seu livro de 2008, A estrutura dos objetos, Kathrin Koslicki defende uma teoria mereológica de cunho aristotélico para descrever a natureza dos objetos concretos. Tal teoria tem como coração a ideia de que objetos compostos são fusões de partes materiais e partes formais, ou seja, ela é uma espécie de neo-hilemorfismo. A principal motivação para a adoção de tal tese é se opor a certas teorias de composição, principalmente o universalismo mereológico. Entretanto, pretendo defender que nenhum dos argumentos de Koslicki é satisfatório para a postulação das partes formais. Isso porque os motivos que a levam ao comprometimento com estas entidades não apenas são injustificados, mas também é possível resolver os problemas levantados pela autora sem o apelo à própria noção de parte formal.

O universalismo mereológico, principal alvo de Koslicki, foi vigorosamente defendido por Lewis (1986 e 1991), se tornando peça central nas discussões metafísicas sobre os objetos concretos nos últimos trinta anos, principalmente no contexto de teorias da persistência como o endurantismo e o perdurantismo. De acordo com Lewis e outros defensores do universalismo, qualquer coleção de objetos possui uma 
fusão, ou seja, gera um novo objeto composto que tem os primeiros como partes. Logo, sejam dois objetos quaisquer, $x$ e $y$, existe um terceiro objeto, $z$, que é sua fusão mereológica. Esta fusão existe independentemente de qualquer relação entre $x$ e $y$. Por exemplo, assim como o meu corpo é a fusão mereológica de todas as suas partes, também existe uma fusão do meu corpo com uma estrela na constelação de Andrômeda.

Além disso, o axioma de extensionalidade da mereologia clássica determina que uma coleção de objetos só pode ter uma única fusão, pois objetos formados com as mesmas partes são idênticos. Porém, ao assumirmos o universalismo mereológico e o axioma de extensionalidade, estamos assumindo que elementos estruturais na composição de uma totalidade são irrelevantes. Afinal, se qualquer coleção de objetos forma um único objeto composto, então não há diferenças entre um objeto ordinário como uma moto, por exemplo, e uma pilha formada pelas partes desta moto. Dado que as peças formam uma única totalidade independentemente de seu arranjo, podemos descartar qualquer contribuição que o arranjo destas peças possa exercer para a existência do todo.

Contra este resultado, que parece absurdo, Koslicki introduz a ideia de que totalidades são formadas por partes materiais e partes formais, em que as últimas são as responsáveis por introduzir o aspecto estrutural que falta ao universalismo. Ou seja, no modelo proposto por ela, a estrutura de uma totalidade é uma de suas partes: ao invés de afirmarmos que uma totalidade é estruturada de tal e tal modo, devemos afirmar que uma totalidade possui esta ou aquela estrutura. Uma vez que a dicotomia aqui se dá entre um elemento material e um elemento formal, pareceria intuitivo afirmar que as partes formais são entidades abstratas, ao contrário das partes materiais, que seriam entidades concretas. Contudo, a própria Koslicki não deixa claro qual é o estatuto ontológico de tais partes. ${ }^{1}$ Para manter o espírito aristotélico de sua teoria, assumirei daqui para frente que, apesar de não serem materiais, tais partes existem de forma imanente, id est presentes nos objetos concretos dos quais são partes.

Se esta tese for verdadeira, Koslicki é capaz de postular uma versão mais forte do axioma de extensionalidade, a saber, uma versão segundo a qual duas totalidades são idênticas se, e somente se, possuem todas as suas partes materiais $e$ formais em comum. Isso garante, por exemplo, que uma moto e uma pilha de peças não podem ser idênticas entre si - a primeira possui aspectos estruturais que a última não possui. Além disso, ela também poderá rejeitar o universalismo, visto que a existência de totalidades ficará restrita apenas a totalidades formadas por partes materiais e formais. Se supusermos a tese (bastante plausível) de que não existem estruturas para meros agregados, então só existem compostos integrais, ou seja, objetos compostos a partir de um princípio organizacional, segundo o qual cada uma de suas partes contribui de maneira relevante ${ }^{2}$ para a existência da totalidade.

No entanto, Koslicki não assume a existência destas partes como algo primi- 
tivo: pelo contrário, ela parte de dois argumentos para introduzir estas entidades. O primeiro argumento diz respeito ao princípio de suplementação fraca da mereologia clássica. O segundo leva em consideração um argumento envolvendo um regresso ao infinito de totalidades, que surge quando assumimos que o todo é mais do que a soma de suas partes. A meu ver, ambos os argumentos são equivocados.

\section{Partes formais e o princípio de suplementação fraca}

A primeira motivação de Koslicki para postular a existência de partes formais em adição às partes materiais de uma totalidade é a possibilidade de resolver certos problemas clássicos, como, por exemplo, o que ela chama de problema da fundação (grounding problem) e, também, o problema da constituição. Segundo ela, o primeiro problema diz respeito à questão sobre o que fundamenta a diferença entre objetos numericamente distintos, porém espaço-temporalmente coincidentes. Os casos problemáticos em questão são puzzles clássicos, como o da estátua de argila (Wiggins 1968 e Lewis 1976): uma estátua e a argila do qual ela é feita parecem ser objetos distintos porque possuem propriedades distintas - sejam estas propriedades modais, temporais ou disposicionais. Ao mesmo tempo, nós não conseguimos fundamentar estas diferenças pelo fato desses objetos serem extremamente semelhantes, e, intuitivamente, idênticos: parece razoável pensar que a estátua simplesmente é a argila da qual ela é feita. $O$ segundo problema é semelhante ao primeiro, e diz respeito à questão sobre a possibilidade de uma análise da relação entre um objeto e aquilo do qual ele é constituído. No caso da estátua de argila, qual é a relação entre ambas?

Portanto, os dois problemas estão relacionados intimamente: enquanto o primeiro busca um esclarecimento da suposta diferença entre objetos coincidentes, o segundo busca um esclarecimento da relação entre algo constituinte e algo constituído. Parece claro que uma resposta a um dos problemas lançaria luz sobre o outro. Por exemplo, se assumirmos que a resposta para o problema da constituição é analisar a relação de constituição material como sendo a relação de identidade (Wiggins, opus citatum), então o problema da fundamentação desaparece. Isso ocorre porque, se a estátua e a argila são idênticas, então não há diferenças entre elas para serem explicadas. É claro que, agora, o trabalho do adepto desta tese de constituição como identidade será o de mostrar que estas supostas diferenças entre os objetos em questão são meramente aparentes: por definição, objetos idênticos não podem ser distintos.

Como dito acima, Koslicki acredita que a postulação de partes formais pode resolver ambos os problemas, e, além disso, ela acredita que tal postulação é legitimada por um princípio da Mereologia extensional clássica que, segundo ela, é constitutivo do próprio significado da noção de parte própria: o princípio de suplementação fraca. De maneira informal, podemos afirmar que $x$ é parte própria de $y$ se $x$ é parte de $y$ 
e eles são distintos: a minha mão claramente é parte própria de mim, visto que ela não apenas é parte de mim, como também é distinta de mim. Tendo isso em vista, o que o princípio de suplementação fraca determina é que uma totalidade não pode ser composta por uma única parte própria (Simons 1987, p.26-28).

A ideia é bastante intuitiva, e pode ser ilustrada da seguinte maneira. Digamos que exista, ex hypothesi, uma totalidade formada por uma única parte própria. Então teríamos um cenário em que uma totalidade é formada por uma única parte que é distinta do todo. Mas se a parte é distinta do todo, então isso significa que a sua subtração deveria deixar uma sobra ou diferença. No entanto, quando subtraímos a (única) parte própria em questão, vemos que não sobra nada distinto dela, e, com isso, concluímos que não havia uma totalidade formada por aquela (única) parte própria. Portanto, por reductio, vemos que não é possível haver uma totalidade formada por uma única parte própria.

O objetivo de Koslicki é usar este princípio para introduzir necessariamente as partes formais. Para isso, ela parte do seguinte exemplo:

Suponha (...) que o mundo contenha objetos que pertencem ao tipo 'pedaço de argila' e objetos que pertencem ao tipo 'estátua'; então, nada parece ser um obstáculo para a criação de uma nova estátua a partir de um único ingrediente pré-existente, um pedaço de argila, apenas pelo rearranjo das partes da argila. Uma vez que uma mudança deste tipo é compatível com as condições de persistência que nós atribuímos ordinariamente a pedaços de argila, não há razões para pensarmos que a argila deixa de existir como um resultado de ter sido rearranjada. (Koslicki 2008, p.179)

No cenário proposto, existem dois objetos concretos: ${ }^{3}$ (a) uma estátua (digamos, a estátua de um ser humano) e (b) um pedaço de argila, de modo que o primeiro é criado a partir do outro. Ela segue argumentando a partir daí que a estátua não é idêntica ao pedaço de argila simplesmente pelo fato de que, via Lei de Leibniz, nós podemos identificar propriedades distintas em ambas as entidades, sejam elas propriedades modais (a argila poderia sobreviver ao ser moldada no formado de uma bola; a estátua não poderia), temporais (antes de constituir a estátua, a argila estava moldada no formato de um cubo; a estátua não), disposicionais (a argila tem a capacidade de se liquefazer a uma temperatura de $n$ graus; a estátua não ${ }^{4}$ ) ou mesmo mereológica (a estátua pode trocar suas partes e continuar a ser a mesma estátua; a argila não).

É com base nisso que Koslicki dá seu passo fundamental: ela defende que, ao assumirmos que a estátua e o pedaço de argila do qual ela é feita são objetos distintos, a única maneira de os distinguirmos é através do princípio de suplementação fraca. Como este princípio determina que uma totalidade deve possuir pelo menos duas partes próprias, o fato de a estátua ser formada apenas pelo pedaço de argila representaria uma violação dele. A solução é óbvia: se postularmos partes adicionais 
de natureza formal, podemos não apenas manter o princípio intacto, como também explicar a diferença entre a estátua e a argila. Além disso, os objetos param de ser coincidentes, dado que agora eles não compartilham mais todas as suas partes: a estátua possui partes formais que o pedaço de argila não possui.

Aqueles que estão familiarizados com a literatura sobre os problemas envolvendo objetos concretos provavelmente vão perceber que Koslicki parece fazer um salto indevido em sua argumentação. Ela parte do princípio de que a argila constitui a estátua e conclui que a estátua é composta pela argila. Que este é um salto gritante, pode ser visto pelo fato de que as relações de constituição material e composição mereológica são completamente distintas. A primeira é uma relação do tipo um-um, id est, a relação entre um objeto e aquela substância da qual ele é feito. A segunda, por sua vez, é uma relação do tipo um-muitos, a relação entre um objeto e suas muitas partes. Ora, o princípio de suplementação fraca diz respeito apenas à composição mereológica, e não à constituição material. Ele não nega que uma entidade possa ser constituída de uma única substância. ${ }^{5}$ Se a argila possui partes, então simplesmente podemos afirmar que a argila constitui a estátua, mas são suas partes que a compõem. Em resumo, o problema se dissiparia sem qualquer discurso sobre partes formais. Porém, é importante notar que Koslicki dá um passo adicional e analisa a relação de constituição em termos da relação de composição, com a definição:

(AMC) Análise Mereológica da Constituição: Alguns objetos, $m_{1} \ldots m_{n}$ constituem um objeto, $\mathrm{O}$, apenas no caso em que $m_{1} \ldots m_{n}$ são os componentes materiais de $\mathrm{O}$, i.e., $m_{1} \ldots m_{n}$ estão entre as partes próprias de $\mathrm{O}$ que satisfazem as restrições ditadas pelos componentes formais $f_{1} \ldots f_{n}$. (Koslicki 2008, p.179)

Tendo feito este movimento, podemos ver que o problema central de sua argumentação é que ela abusa do princípio de suplementação fraca, torcendo-o para obter o resultado desejado. Ao contrário do que ela afirma, a introdução das tais partes formais não é ditada pelo princípio em questão. Devemos ter em mente que o princípio de suplementação fraca afirma apenas que qualquer fusão própria deve ser constituída de duas partes próprias. Isso é suficiente para bloquear o argumento de Koslicki antes que ele comece a alçar voo: o caso que ela sugere que nós concebamos é impossível de acordo com o princípio para começo de conversa. Ainda que fosse concebível admitir que as únicas coisas que existem no universo são um pedaço de argila e uma estátua, nós não estaríamos legitimados a fazer a primeira suposição do argumento, que é afirmar que a estátua é composta a partir da argila.

O máximo que nós poderíamos supor, de acordo com o princípio de suplementação fraca, é que a estátua e a argila, sendo objetos distintos, compõem uma totalidade na medida em que são partes próprias dela. Isso, inclusive, estaria mais alinhado 
com a tese geral da própria Koslicki, a saber, de que os elementos formais de um objeto também são partes dele. ${ }^{6}$ Portanto, assuma que existem duas coisas no universo: uma massa material de argila e uma estrutura formal de estátua. A fusão deles será uma totalidade da qual ambos são partes próprias. Apesar de estar de acordo com a tese geral de Koslicki, esta versão não garante a ela que as tais partes formais existam. E o que ela procura usando o argumento baseado no princípio de suplementação fraca é exatamente um motivo para introduzir estas partes sem ter que tirá-las da cartola.

Mas então, qual é o real motivador da tese de Koslicki? Trata-se do outro princípio da Mereologia extensional clássica mencionado no início deste artigo, a saber, o axioma de extensionalidade. Lembremos que, segundo este axioma, duas totalidades são idênticas se, e somente se, possuírem todas as suas partes em comum. Em outras palavras, duas totalidades são idênticas se forem extensionalmente equivalentes. Se esse princípio for verdadeiro, então o caso proposto por Koslicki envolvendo a estátua e a argila se torna problemático: a estátua e a argila compartilham todas as suas partes - ou melhor, a única parte em questão, que é a própria argila. Logo, tais objetos devem ser idênticos. Mas então, como explicar suas diferenças qualitativas? Surge o problema da fundamentação. A única forma de resolver este problema, segundo Koslicki, é diferenciando os objetos em questão mereologicamente, e, se não há mais partes materiais para cumprir este papel, então a resposta é apelar para partes formais. Porém, como introduzir estas partes? Ora, uma vez que já assumimos ex hypotesi que essa totalidade só possui uma única parte material, parece que o princípio de suplementação fraca agora nos obriga a aceitar que devem existir mais partes para suplementar o todo: entram em cena as partes formais.

Observe que o princípio de suplementação fraca só passa a ditar a introdução de partes formais para explicar uma suposta diferença mereológica que deveria existir porque o axioma de extensionalidade estaria identificando os dois objetos em questão. É claro que, se o princípio de suplementação fraca exigir realmente a introdução de partes formais, então o axioma de extensionalidade deixa de ser uma ameaça, porque os objetos em questão de fato irão diferir em partes. E é importante para Koslicki que o axioma de extensionalidade, em sua versão clássica, seja bloqueado, porque este axioma parece tornar irrelevante qualquer tipo de discurso sobre estrutura; não importa a estrutura de um objeto: se ele mantém as mesmas partes, então ele se mantém o mesmo. Isso leva ao resultado paradoxal mencionado anteriormente de que um carro e a pilha de peças desconexas deste mesmo carro são idênticos.

Mas o primeiro argumento de Koslicki ainda tem outro problema. Afinal, tudo indica que devemos conceber a porção de argila como um objeto composto. $\mathrm{O}$ fato de ela ser um composto homogêneo, como uma porção de água ou ouro, não faz diferença. Ela possui partes. Partes, inclusive, que são formadas por objetos heterogêneos, como átomos de tais e tais substâncias. Portanto, a argila não é atômica, como o ex- 
emplo de Koslicki parece querer forçar. Logo, quando dizemos que a argila compõe a estátua, o que estamos dizendo é que as diversas partes da argila se arranjam de tal e tal modo que elas compõem uma estátua. Se assumirmos a posição ortodoxa, o que temos aqui não são dois objetos coincidentes compartilhando uma única parte, mas sim dois objetos coincidentes compartilhando diversas partes, partes estas que ao mesmo tempo compõem um pedaço de argila e uma estátua. Portanto, mesmo que o axioma de extensionalidade exija uma diferença em termos mereológicos para diferenciar estes objetos que compartilham todas as suas (muitas) partes, nós não poderemos recorrer mais ao princípio de suplementação fraca para introduzir estas partes formais.

Eu gostaria de reforçar a ideia de que o exemplo de Koslicki precisa assumir que a argila é atômica - pelo menos num certo sentido - caso contrário, ele não é capaz de atingir seu objetivo. Observe que ela está supondo que a estátua é formada por uma única parte própria, a argila. É apenas assim que o exemplo é capaz de violar o princípio de suplementação fraca. Mesmo que ela não esteja assumindo explicitamente que o pedaço de argila é um átomo extenso - é uma evidência textual que ela diz que a estátua é criada a partir dos rearranjos das partes da argila - ela está assumindo, implicitamente, que o pedaço de argila é, num certo sentido, atômico - porque ele é um objeto composto, e não uma mera pluralidade de partes. Mas, obviamente, esta não é uma saída: pela transitividade da relação 'ser parte de', todas as partes da argila são partes da estátua mesmo que a argila fosse supostamente a única parte da estátua. Em resumo, a única forma de construir o exemplo de Koslicki seria se imaginássemos um átomo no sentido literal do termo, sem qualquer tipo de complexidade interna e, adicionalmente, imaginássemos que este átomo poderia compor outro objeto - uma estátua atômica? Mas isso parece ser inconcebível, ou no mínimo forçoso; a alternativa a este caso seria a negação total da transitividade da relação 'ser parte'.

Alguém poderia tentar salvar o cenário de Koslicki afirmando que há a possibilidade de imaginarmos que, ao invés de argila mundana, a estátua fosse feita de uma substância extensa, mas sem partes, como uma espécie de gosma cujas regiões só pudessem ser definidas através de seu contorno, ou figura geométrica. Essa seria uma versão mais sofisticada da tese de que a argila é atômica, apesar de extensa. Minha resposta a esse cenário seria afirmar que o fato de ser possível diferenciar sub-regiões espaciais da substância em questão já é suficiente para afirmar que ela possui partes - por exemplo, ela possui o lado direito e o lado esquerdo, etc. Note, ainda, que o cenário original determina que a estátua seja construída a partir do rearranjo das partes da argila. No cenário alternativo, isso significaria rearranjar o contorno ou figura geométrica da substância em questão. Mas, novamente, isso seria simplesmente rearranjar as sub-regiões da substância, e parece inevitável identificar estas sub-regiões com suas partes. O que estou sustentando em minha resposta a 
este cenário alternativo é que a noção de um átomo extenso é problemática: dado que tudo o que é extenso é divisível em sub-regiões, estas sub-regiões são, ipso facto, suas partes próprias.

A essa altura, o defensor desse contraexemplo poderia insistir na legitimidade do cenário proposto e argumentar que minha resposta só faz sentido em uma concepção newtoniana de espaço, onde suas coordenadas são absolutas e ele existe por si só, como um recipiente no qual os objetos estão contidos. Entretanto, se o espaço for entendido como relativo e, se apenas a substância em questão existisse, então seria necessária a conclusão de que não há como diferenciar suas sub-regiões. Ou seja, parece não haver um lado direito ou esquerdo, acima ou abaixo se o espaço é relativo e só esta substância existe.

O ponto, obviamente, passa a ser então se o exemplo de Koslicki pode ser concebível neste cenário em particular. ${ }^{7}$ Afinal, se já é difícil conceber a própria substância em questão, é ainda mais difícil imaginar como ela estaria arranjada como uma estátua se não é possível identificar suas sub regiões. Independentemente do segundo cenário ser possível ou não, a minha resposta é que nem mesmo essa versão implicaria na aceitação de partes formais: o que o cenário mostra é que a estátua não pode ser atômica, sob pena de violarmos o princípio de suplementação fraca, mas ele é mudo quanto à natureza destas partes. Assim como Koslicki assume que seja necessário postular as partes formais para que o exemplo não viole o princípio em debate, um oponente poderia simplesmente supor que devemos postular mais partes materiais, sob pena do exemplo em si mesmo ser inconcebível, a menos, como dito na digressão acima, que aceitemos a noção de átomo extenso.

\section{Partes formais e o regresso ao infinito}

Passemos então ao segundo ponto mencionado acima: a ideia de que uma totalidade é mais do que a soma de suas partes leva a um regresso infinito? O dilema parece ser o seguinte: suponha que uma totalidade é mais do que as suas partes tomadas em conjunto, ou seja, que ela seja algo distinto de suas partes. Nesse caso, se o todo é mais do que uma soma de partes, então ou bem essa coisa distinta das partes é atômica ou complexa: se ela for atômica, então haverá uma nova soma de partes (as partes anteriores mais a totalidade distinta delas), ad infinitum; se ela for um novo composto de partes, então esse novo composto também será mais do que a soma de seus elementos/partes, gerando outro composto, ad infinitum.

De acordo com Harte (2002), o primeiro a formular este paradoxo foi Aristóteles em sua Metafísica (Livro Zeta, cap.17, 1041b12-33). ${ }^{8}$ No entanto, Koslicki discorda desta posição e argumenta que, segundo o próprio Aristóteles, este paradoxo só surge se tomarmos a totalidade como pertencendo à mesma categoria ontológica de suas 
partes. Em outras palavras, se o todo for um objeto concreto formado apenas por objetos concretos, então o regresso de fato surgiria. Porém, se assumirmos que o todo possui complexidade ontológica, isto é, é composto por entidades de categorias distintas, então o regresso não aconteceria. A ideia parece ser intuitiva: a diferença entre uma totalidade e suas partes tomadas em conjunto está na estrutura/arranjo que o todo possui e sua coleção de partes materiais não. No entanto, uma vez que as partes materiais se juntam às partes formais para compor um objeto concreto, este objeto distinto que surge não se soma novamente às suas partes num regresso ao infinito porque não existem outras partes formais para gerar essa nova fusão. Aqui, as partes formais podem ser entendidas como uma espécie de receita ou blueprint que determina a organização das partes materiais. O que Koslicki parece estar assumindo é que não existiriam partes formais de segunda ordem, apenas de primeira. Ou seja, existem apenas partes formais que operam sobre partes materiais, mas não partes formais que operam sobre partes materiais $e$ partes formais.

Novamente, se este é um ponto de partida para inserir a noção de parte formal, ele é um ponto de partida equivocado. O problema aqui claramente é análogo à formação dos conjuntos potência em teoria dos conjuntos. De acordo com a teoria dos conjuntos, um conjunto qualquer é capaz de gerar um conjunto potência com cardinalidade maior que a sua própria. Tome, por exemplo, o conjunto $A=\{a\}$. O conjunto potência de $A$ é o conjunto $B=\{\{\},\{a\}\}$, a saber um novo conjunto formado pelo anterior e todas as suas "partes constituintes", por assim dizer. ${ }^{9}$ É claro que este processo pode se repetir infinitamente, e agora teríamos o conjunto potência de $B$, a saber, $C=\{\{\},\{\{\}\},\{\{a\}\},\{\{\},\{a\}\}\}$, e assim ad infinitum.

Curiosamente, o que é um fenômeno comum em teoria dos conjuntos é algo escandaloso em mereologia. E isso esclarece ainda mais a distinção entre totalidades e conjuntos: não existe o conceito de totalidade potência na Mereologia extensional clássica, e, portanto, não se pode assumir que uma totalidade e suas partes se combinem adicionalmente para formar outra totalidade distinta da primeira. E, contra Koslicki, isso não tem a ver com distinções ontológicas entre partes ou com a introdução de partes formais. Isso tem a ver simplesmente com três pontos inerentes à natureza das totalidades: (i) não existem totalidades unitárias em mereologia; (ii) duas totalidades que compartilham todas as suas partes são idênticas; (iii) um objeto não pode ser parte de outro mais de uma vez. A noção de conjuntos unitários (singletons) era algo que perturbava o criador da Mereologia extensional clássica, Stanisław Leśniewski, tanto quanto a noção de conjunto vazio, e isso o levou a desenvolver esta teoria formal como uma alternativa à teoria dos conjuntos (Leśniewski 1916). A menos que tomemos conjuntos como entidades completamente abstratas ou conceitos, a questão lesniewiskiana continua válida: como é possível que de um único objeto, a saber, $x$, seja possível postular a existência de outro objeto, seu conjunto unitário $\{x\}$ ? Afinal de contas, o que distingue $x$ de $\{x\}$ ? 
Se nós não admitirmos a existência de conjuntos unitários, então é impossível construir conjuntos potência, porque o conjunto potência de $\{a, b\}$, por exemplo, depende, no mínimo da existência de $\{a\}$ e $\{b\} .{ }^{10}$ Se $\{a\}$ e $\{b\}$ não fossem possíveis, então o conjunto potência de $\{a, b\}$ seria simplesmente ele mesmo. E, como em mereologia não existem totalidades unitárias, então a partir de uma totalidade $x=[a+b]$ não é possível formar outra totalidade, porque $a$ e $b$, por si só, não formam nada composto: a totalidade potência de $x$ é ele mesmo, portanto, não é algo distinto que pudesse gerar um regresso ao infinito. Isso é estabelecido simplesmente por (i) e (ii).

Em conformidade com isso, é importante também ressaltar o papel de (iii) neste contexto. Vamos supor, ex hypothesi, que exista uma totalidade potência de $x=[a+$ $b]$, a saber, $Y=[x+a+b]$; Isso claramente violaria o princípio mereológico de que um objeto não pode ser parte de outro mais de uma vez. Nesse caso, $a$ e $b$ seriam partes de $Y$ duas vezes: primeiro por que elas são, hipoteticamente, parte de $Y$, e segundo porque elas são partes de $x$, que é outra parte de $Y$. Por transitividade, elas são partes de $Y$ novamente! Mas isso é um absurdo: eu não posso ter o meu braço como parte de mim duas vezes. ${ }^{11}$ Note que no caso do conjunto $A=\{a, b\}$, seu conjunto potência, $B=\{\{\},\{a\},\{b\},\{a, b\}\}$ não tem $a$ e $b$ como elementos mais de uma vez, ${ }^{12}$ porque $a$ e $\{a\}$ são objetos distintos. Novamente, a única forma de haver uma totalidade potência em mereologia seria assumindo a noção altamente problemática de totalidade unitária, o que violaria o princípio de suplementação fraca.

É importante observar que há uma hierarquia entre os pontos (i)-(iii) colocados acima. Os pontos (i) e (ii) podem ser considerados independentes um do outro. O fato de dois objetos serem idênticos se compartilharem todas as suas partes continuaria sendo válido independentemente de haver totalidades unitárias ou não. Por outro lado, o princípio (iii) pode ser intuitivamente derivado de (ii) e do princípio clássico de identidade: se uma totalidade possui dois objetos idênticos como partes, então estes objetos são, na realidade, apenas um objeto. Logo, a totalidade em questão possui um único objeto como parte.

Uma possível objeção a este princípio seria apelar para a noção de granularidade mereológica. Em linhas gerais, granularidade poderia ser caracterizada como "o nível de precisão que resulta da limitação de uma coleção de entidades básicas (grânulos) em termos de que informação de um determinado tipo é formulada" (Burkhardt, Seibt \& Imaguire 2017). Assim, alguém poderia afirmar que o mesmo objeto é parte de uma totalidade em diversas vezes por estar presente em diversas granularidades. Por exemplo, o coração é parte do corpo se assumirmos uma granularidade no nível dos tecidos porque o coração é um músculo. Mas ele também é parte do corpo se assumirmos uma granularidade no nível dos órgãos, porque ele é um dos órgãos do corpo. Aparentemente, isso parece significar que o coração é parte do corpo humano duas vezes: como tecido e como órgão. Porém, essa aparência é enganadora. $\mathrm{O}$ 
coração não é parte do corpo humano duas vezes porque o corpo humano só existe em certo nível de granularidade. Se estivermos falando do nível granular dos tecidos, não há uma camada mereológica acima disso. Da mesma forma, se estivermos no nível granular dos órgãos, também não podemos falar do corpo como totalidade. Devemos falar apenas de uma pluralidade de órgãos. Por fim, o princípio em disputa poderia ser fortalecido para acomodar a diferença entre níveis granulares, de tal modo que um objeto nunca pode ser parte de outro objeto mais de uma vez no mesmo nível de granularidade. Observe que o exemplo dado não viola essa versão do princípio.

Voltando ao ponto anterior a esta digressão, a saber, a disputa entre Harte e Koslicki acerca do regresso aristotélico: o regresso ao infinito que supostamente ameaçaria qualquer tentativa de distinguir as partes do todo composto por elas não é algo intrínseco à distinção entre tais objetos, como Harte pensa, e também não tem a ver com uma suposta complexidade ontológica colocada por Koslicki como mais um pretexto para introduzir partes formais. Ele é algo que só poderia ocorrer se totalidades se comportassem como conjuntos. Como isso não é o caso, não é possível criar um regresso nem mesmo se o todo for um objeto concreto adicional às suas partes. Apesar de ambas as autoras estarem equivocadas neste ponto, é importante para Koslicki que Harte esteja enganada apenas parcialmente: o regresso deve ser uma ameaça potencial. Uma ameaça cujo remédio é a postulação de partes formais. Mas como espero ter mostrado aqui, independentemente das motivações de Aristóteles para postular a forma como parte do composto em sua filosofia, o hilemorfismo neo-aristotélico de Koslicki não é justificado, ou, pelo menos, não pelos motivos dados pela autora e discutidos neste artigo - o princípio de suplementação fraca e o regresso aristotélico.

\section{Conclusão}

A postulação de partes formais proposta por Koslicki para resolver problemas relacionados à estrutura dos objetos concretos é baseada em dois argumentos centrais: um argumento a partir do princípio de suplementação fraca e um argumento a partir de um suposto paradoxo de regresso ao infinito de totalidades que são distintas de suas partes. Como vimos, ambos os argumentos são falhos: o primeiro por abusar da intuição por trás do princípio de suplementação fraca e o segundo por introduzir na Mereologia extensional clássica um comportamento para totalidades que só se aplica a conjuntos.

Por um lado, o princípio de suplementação fraca determina que toda totalidade deve possuir pelo menos duas partes. Portanto, ou bem o pedaço de argila que é parte da estátua é um objeto complexo, ou bem ele não é parte da estátua, ou então 
ele e a estátua são partes de outro objeto. Por outro lado, não apenas não existe totalidade potência em Mereologia Clássica, o que por si só impede a formação de totalidades ad infinitum, como também não é possível que um mesmo objeto seja parte de uma totalidade mais de uma vez, tanto simpliciter quanto levando em conta diferentes níveis de granularidade. Em todos os casos examinados, a postulação de partes formais é completamente desprovida de motivação.

\section{Referências}

Aristóteles. 1991. Metaphysics. In: The Complete Works of Aristotle. Volume 2, p.1552-1728. Trad. W. D. Ross. Oxford: Oxford University Press.

Bennet, K. 2013. Having a Part Twice Over. Australasian Journal of Philosophy 91(1): 83-103. Burkhardt, H.; Seibt, D.; Imaguire, G. 2017. Handbook of Mereology. Munique: Philosophia. Cotnoir, A. J. 2013. Strange Parts: The Metaphysics of Non-classical Mereology. Philosophy Compass 8(9): 834-845.

Effingham, N. \& Robson, J. 2007. A Mereological Challenge to Endurantism. Australasian Journal of Philosophy 92(1): 633-640.

Harte, V. 2002. Plato On Parts and Wholes. Oxford: Clarendon Press.

Koslicki, K. 2008. The Structure of Objects. Oxford: Oxford University Press.

Leśniewski, S. 1916. Foundations of the General Theory of Manifolds. Moscow.

Lewis, D. 1976. Survival and Identity. In: A. Rorty (ed.), The Identities of Persons. Berkeley: University of California, p.17-40.

Lewis, D. 1986. On the Plurality of Worlds. Oxford: Blackwell Publishers.

Lewis, D. 1991. Parts Of Classes. Oxford: Blackwell Publishers.

Merricks, T. 2001. Objects and Persons. Oxford: Oxford University Press.

Simons, P. 1987. Parts: A Study in Ontology. Oxford: Oxford University Press.

Van Inwagen, P 1990. Material Beings. Ithaca e London: Cornell University Press.

Wiggins, D. 1968. On Being in the Same Place at the Same Time. Philosophical Review 77(1): 90-95.

\section{Notas}

${ }^{1}$ Ao final de seu livro, Koslicki aproximará a noção de 'parte formal' da noção de 'tipo natural', sugerindo que estes aspectos estruturais são entidades que se assemelham a universais.

${ }^{2}$ Em geral, a relevância de uma parte para a composição de uma totalidade é tomada como um critério para responder à questão especial da composição, formulada por Peter van Inwagen em seu livro de 1990, Material Beings: quando a composição ocorre? Os principais candidatos ao posto de critério relevante são a tese de contato físico, organicismo e funcionalismo.

${ }^{3}$ Apesar de a estátua não poder ser separada da estátua, é comum a literatura sobre o tema tratá-la como um objeto concreto, numericamente distinto da estátua. Se a estátua fosse um objeto abstrato, então seria difícil ver como ela poderia ser formada a partir da argila.

${ }^{4}$ Talvez isso possa soar contraintuitivo, afinal, se o ponto de fusão da argila é de, digamos, $1.700{ }^{\circ} \mathrm{C}$, então a estátua se liquefaz na mesma temperatura. Observe, contudo, que a física 
não diz nada sobre pontos de fusão de objetos ordinários como estátuas, mesas, carros, etc. Portanto, apesar de fazer sentido falar no ponto de fusão de pedaços de argila, não faz sentido falar do ponto de fusão de estátuas de Júlio César. Isso se torna ainda mais evidente se adicionarmos a suposição de que a mesma estátua pode ser feita de materiais distintos: se pudermos substituir gradualmente a argila por outra substância, seu ponto de fusão será outro, mas não parece correto afirmar que a mesma entidade possui pontos de fusão distintos. Logo, a argila possui certas disposições que a estátua não possui.

${ }^{5}$ O que seria bastante contraintuitivo: temos diversos exemplos ordinários de objetos constituídos de uma única substância material, tais quais mesas de madeira, chapas de aço, etc.

${ }^{6}$ Para ser mais preciso, nessa versão do cenário existiriam as partes formais relativas à estrutura de uma estátua e um pedaço de argila que, ao se combinarem pela relação de composição mereológica, gerariam a estátua em questão.

${ }^{7}$ Que o espaço seja absoluto ou relativo, é uma questão empírica. Uma vez que a ciência atual é feita no contexto da relatividade einsteiniana, é mais seguro assumir que o espaço seja relativo. A questão em debate passa a ser (1) se é possível conceber átomos extensos e (2) se é possível conceber átomos extensos sendo o espaço relativo e onde apenas um átomo extenso existe.

${ }^{8}$ Esta referência segue o formato de citação padrão das obras de Aristóteles utilizando a numeração Bekker.

${ }^{9}$ Coloco a expressão entre aspas porque a relação "ser elemento de" (ou "estar contido em") não é obviamente mereológica.

${ }^{10}$ Pelo menos a princípio, o conjunto vazio não precisaria ser postulado.

${ }^{11}$ Aqui eu estou deliberadamente ignorando casos bizarros envolvendo viagens no tempo, como aqueles apresentados por Effingham \& Robson (2007). Para uma discussão mais profunda sobre o que significa um objeto ser parte de outro mais de uma vez, ver Bennet (2013) e Cotnoir (2013), inter alia.

${ }^{12} \mathrm{Na}$ verdade, $B$ não tem $a$ e $b$ como elementos em absoluto, porque a relação de ser um elemento não é transitiva.

\section{Agradecimentos}

Uma versão preliminar das ideias defendidas neste artigo foi discutida com colegas da área de metafísica analítica no 11th Principia International Symposium de 2019 e em outros encontros informais. Gostaria de agradecer a todos que assistiram as minhas apresentações e contribuíram para o resultado final deste trabalho com suas críticas e sugestões. Gostaria de agradecer especialmente ao Gustavo Lyra e ao Valdenor Monteiro Brito Júnior pelos contraexemplos envolvendo os casos do átomo extenso, da relação entre mereologia e granularidade e da concepção relativa do espaço, bem como ao Tiago Ponti pela leitura crítica das versões iniciais deste manuscrito e ao João Pedro Bellas pela revisão textual. Finalmente, gostaria de agradecer à Coordenação de Aperfeiçoamento de Pessoal de Nível Superior (CAPES) pela bolsa de doutorado que recebi durante o período de elaboração deste manuscrito. 